\title{
Strategies as Discursive Constructions: The Case of Airline Alliances
}

\author{
Eero Vaara, \\ E.M. Lyon \\ (evaara@hkkk.fi).

\section{Birgit Kleymann} \\ Helsinki School of Economics

\section{Hannu Seristö} \\ Helsinki School of Economics
}

E.M. Lyon, 23, avenue Guy de Collongue, BP 174

69132 Lyon Ecully Cedex, France 


\section{ABSTRACT}

In this paper, we argue that by examining the discursive elements in strategy talk we can contribute to our understanding of the myriad of microprocesses and practices that make up strategies. We focus on airline alliances as a particularly illustrative case. Based on a critical discourse analysis of an extensive material of strategy talk on airline alliances, we point to five types of discursive practices that characterize strategizing in this context in 1995-2000: (1) problematization of traditional strategies; (2) rationalization, objectification and factualization of alliance benefits; (3) fixation of ambiguous independence concerns; (4) reframing of cooperation problems as 'implementation' issues; and (5) naturalization of alliance strategies. While we want to emphasize the context-specificity of these practices, we claim that similar types of discursive practices are also likely to be an inherent part of strategizing in other settings.

\section{INTRODUCTION}

Intuitively, we all know that strategies are discursive constructions.We are involved in inventing them, or they seem to be forced upon us. They are created and recreated when we make sense of our work and organizations and talk about them. They spread across organizations, organizational fields and industries. They legitimate ways of formulating strategies and can be used as rhetorical devices to justify specific actions. Over time, the ideas may also become the norm for strategic thinking and action in specific organizational fields.

Existing strategy research has, however, paid little attention to the discursive processes involved in strategizing. Many scholars have probably felt that the social construction of reality is outside the core of strategy research and should be left to the sociologists. Others have viewed the rhetorical or discursive as interesting side issues, but not as important as the 'real' processes involved in strategizing. In fact, few strategy scholars have explicitly taken up the role of discourse in strategy work (Barry and Elmes, 1997; Hendry, 2000; Knights and Morgan, 1991).

Therefore, we focus in this paper on the discursive construction of strategies. We argue that by examining the discursive elements involved in strategy talk we can contribute to our understanding of the myriad of micro-processes and practices that make up strategies. We 
focus on airline alliances as a particularly illustrative case. In brief, alliances emerged during the 1990 s as the dominant strategy alternative for airlines. Rather than remaining mere 'empty rhetoric' or serving only symbolic or ceremonial purposes, alliances have also become an essential part of the task environment of airlines; this has happened despite discouraging experiences of cooperation (see e.g. Lindquist, 1999; Segil, 1998).

Based on a critical discourse analysis (Fairclough, 1997) of extensive material on strategy talk in airline alliances from 1995 to 2000, we point to five types of discursive practices that characterized strategizing in this context: (1) problematization of traditional strategies; (2) rationalization, objectification and factualization of alliance benefits; (3) fixation of ambiguous independence concerns; (4) reframing of cooperation problems as 'implementation' issues; and (5) naturalization of alliance strategies. While we want to emphasize the context-specificity of these practices, we claim that similar types of discursive practices are also likely to be an inherent part of strategizing in other contexts.

\section{PROBLEMS IN TRADITIONAL APPROACHES TO STRATEGIZING}

Researchers have lately pointed to problems in the traditional ways of conceptualizing 'strategy' as planning- and implementation-oriented processes. First, there seems to be an inbuilt lack of appreciation of the social aspects in strategizing when viewing organizations or managers as rational decision-makers. Strategy researchers have specifically pointed to the problems created when neglecting the cultural (see e.g. Norrman, 1993), political (see e.g. Mintzberg, 1983; Pettigrew, 1973) and socially structured (see e.g. Hendry, 2000; Whittington, 1993) aspects of strategizing in particular organizational contexts. Therefore, some strategy scholars have emphasized the role of wider social context of strategizing and different types of social networks in these processes (see e.g. Pettigrew, 1992). At the same time, others have called for attention to the (largely neglected) 'everyday' microactivities and practices instead of 'grand strategies' of formal decision-making (see e.g. Johnson and Bowman, 1999; Johnson and Huff, 1998; Johnson, Melin and Whittington, 2003).

Second, strategy work has traditionally been defined as teleological activity where intentions guide organizational action. This has created problems, for example, in dealing with the classical observations of organizational decisionmaking, pointing to the chaotic nature of this social activity where, for example, 'solutions search for the problems' (see e.g. Cohen et al., 1972). Organizational students have also increasingly pointed out that 
organizational sensemaking is retrospective activity; ideas are coined or crystallized only after major decisions have been made or major changes have occurred in the environment. (see e.g. Weick, 1995). As de Bono (1984, p. 143) put it: 'Strategy is good luck rationalization in hindsight'. Such views obviously fit poorly with the classical teleological models.

Third, strategy research has traditionally not distinguished between 'idea' and 'practice' or 'talk' and 'action' in strategizing. This means that researchers have not been able to analytically separate the creative (essentially linguistic) processes through which ideas are generated from the organizational 'reality' that may or may not be well understood by the specific 'strategies' as (linguistic) constructs. As a consequence, there is a lack of understanding of the processes through which particular strategies as concepts, ideas or narratives gain popularity and become legitimated and institutionalized (see e.g. Barry and Elmes, 1997; Hendry, 2000).

Fourth, both contemporary strategy practices and strategy research have been harshly criticized by sociologically oriented scholars because they often seem to (re)produce managerial hegemony and Western world domination. Therefore, many scholars have urged people to develop theoretical and methodological perspectives that would help to understand the subjectification and disciplinary processes involved in strategic management (see e.g. Alvesson and Willmott, 1996; Knights and Morgan, 1991, 1995).

To partially remedy such problems, strategy researchers have recently searched for new ways of conceptualizing 'strategy'. Closely linked with the more general reorientations in management and organization research, 'strategy' has been reconceptualized, for example, as social practice (Whittington, 1993), narrative (Barry and Elmes, 1997; Dunford and Jones, 2000) or discourse (Hardy et al., 2000; Hendry, 2000; Lilley, 2001) oriented activity. In the following section, we draw on this work when elaborating our discursive approach to strategizing. 


\section{UNDERSTANDING STRATEGIES AS DISCURSIVE CONSTRUCTIONS}

Discourse analysis has become an increasingly popular method for examining the linguistic elements in the construction of social phenomena (see e.g. van Dijk, 1997). It has been increasingly adopted by organization and management scholars interested in the social construction of specific organizational ideas or practices (see e.g. Alvesson and Kärreman, 2000; Czarniawska, 1997; Keenoy et al., 1997; Westwood and Linstead, 2001). Of strategy scholars, for example, Barry and Elmes (1997), Hendry (2000) and Lilley (2001) have highlighted and elaborated on the discursive elements in strategizing processes.

The nature of discourse, however, is a question that has divided scholars in social science in general (see e.g. van Dijk, 1997) and in organization and management studies in particular (Alvesson and Kärreman, 2000). In fact, linguists seem to understand discourse as language use, psychologists as cognitions, and sociologists as social interaction (van Dijk, 1997). There are also different levels of analysis extending from utterances to metadiscourses, and different methods ranging from detailed textual analyses to a more abstract analysis of dominant social and societal discourses. The approaches in discourse analysis also vary greatly in terms of the epistemological assumptions concerning discourses. In brief, the most radical constructionists emphasize the role of discourses as the elements through which social reality is created, while the more realist authors emphasize that discourses are only one part of social reality (see e.g. Reed, 2000).

In line with a critical realist perspective on discourse (Fairclough, 1997), we understand discourses as firmly related to specific social contexts and social practices. From this perspective, discourses can be seen as both socially conditioned and socially constitutive. They are socially conditioned in that the discourses are (re)produced in specific settings by particular social actors. However, due to their key role in any social sensemaking activity, they are also socially constitutive. Discourses in very concrete terms (re)construct concepts, objects, subjects and identities by/with which specific social actors have to live.

In this paper, we see discourses as specific ways of speaking and constructing social reality. In this sense, we follow the ideas developed by Barry and Elmes (1997) and Hendry (2000), who emphasize the role of narrative and discursive type of presentation and knowledge in strategizing activities, and the work by Hardy et al. (2000), who point to the processes of discourse mobilization in specific strategy processes. To clarify the key role of 
discourses in strategizing, it is, however, important to point to their 'dual' nature. On the one hand, discourses can be seen as resources that social actors mobilize in strategizing processes (see also Hardy et al., 2000). In the context of strategy creation, obviously top managers, consultants and journalists are the actors who can (re)create and make use of specific discourses. On the other hand, these actors are also significantly bound by (a finite number of) existing context-specific discourses. In this sense, the discourses have specific power over the social actors in particular contexts.

It is precisely this dependence on existing and available discourses that is most interesting for a discursive perspective on strategizing. This is the case as uncovering the discursive roots and linkages of strategy talk makes us see the various kinds of cultural, historical and ideological elements involved. This in particular helps us to understand how strategic ideas gain or do not gain legitimacy in specific contexts. Many people have, for example, pointed to the central role of modernist ideas (see Lyotard, 1979) and specifically the discourse on 'global capitalism' (Fairclough, 2000) as a dominant discourse type in strategy reflections in and around organizations. Within this framework, 'competitiveness improvement', 'globalization' and 'shareholder value' seem to be constructed as dominant objectives, the pursuit of which often legitimizes even the unfortunate consequences of specific strategies.

Although for example Foucauldian approaches give little weight to the actors' own intentions or rhetorical strategies, we believe that they can make intentional use of various discourses. In line with the 'critical realist' approach called for by Reed (2000), we assume that that agents can 'play with discourse' and 'use it in the context of power relations'. This kind of approach is theoretically in line with the 'new rhetoric' (Perelman, 1977; Perelman and Olbrechts-Tyteca, 1958/1971), which emphasizes the role of discourse in argumentation as the speakers have to adapt the discourse to their audience. This means that the actors involved in strategizing are likely to switch from one discourse to another if so required to justify and legitimate specific decisions or actions. Such discourse mobilization may be seen as idiosyncratic, and it is usually very difficult to define the extent to which the discourse used is an intentional choice or a product of the context. Nevertheless, we can think that the actors also make deliberate use of specific arguments or discourses without believing the ideas presented or without the intention to act accordingly, which creates hypocrisy in strategy talk (Brunsson, 1989). 
We can thus understand strategies as discursive constructions created in complex ongoing sensemaking processes. This implies a view on strategy that is effectively captured in Lilley's words: 'Strategy is up there. Right up there. At the top. And above all, the language that it mobilizes, and is mobilized by it, is what puts it there' (Lilley, 2001, p. 66). These constructions can thus be seen as stabilizations of specific organizational intentions. However, while stabilizing specific intentions, these constructions can naturally also destabilize other ideas by offering new alternatives. This can be seen as an essential discursive dynamic in strategizing when it involves reformulation of organizational objectives and identities. What we also want to emphasize here is that these constructions are usually fluid and temporary; this implies methodological problems in trying to uncover the various kinds of meanings associated with organizational strategies.

In this paper, we are in particular interested in the discursive practices involved in the strategizing processes. These discursive practices can be understood as ways of activating and utilizing specific discursive resources in particular contexts. These discursive practices are (re)created in the active sensemaking processes of various actors, but they, in turn, influence the strategizing of others. In a sense, they start to live a life of their own. It is precisely this dualistic role of the discursive practices that we find most interesting in the strategizing context. In a nutshell, the discursive practices are an essential part of the discursive micro-structures that easily pass unnoticed in strategizing processes.

Epistemologically and methodologically, discursive practices are thus problematic objects of study. Nevertheless, we claim that they deserve special attention if we are interested in how specific strategic ideas are legitimated and how these ideas and particular practices become normalized (Foucault, 1980) or naturalized (Fairclough, 1997). To map out such practices, we now turn to our empirical setting: the airline alliances.

\section{THE RESEARCH SETTING: THE EMERGENCE AND INSTITUTIONALIZATION OF AIRLINE ALLIANCES}

Alliancing in today's airline industry seems pervasive - virtually every international airline is forging alliances of some form. Cooperation between airlines can be traced as far back as the 1940s. For instance, Air France has been involved in setting up the operations of many African airlines - Air Afrique, Royal Air Maroc and Tunisair - and still has equity stakes in those carriers. The first carrier to develop a strategy around alliances was the Scandinavian 
airline SAS. In the mid- 1980s, the representatives of SAS started to talk of the importance of alliances between smaller airlines in order to face the tougher competition from the largest carriers. During the latter part of the 1980s and the early 1990s, SAS tried to build alliances of various types with other carriers but eventually did not succeed in creating successful alliances.

The first major multi-partner alliance was that between Delta Air Lines, Singapore Airlines and Swissair in the early 1990s. That alliance raised a fair amount of discussion in various forums, perhaps because it showed that cooperation between competing airlines was more difficult than envisioned. Eventually that alliance failed to deliver much benefit to the airlines and ended rather disappointingly. In the 1990s, the number of alliances in the airline industry grew each year, and the scene also became very volatile; alliances were broken, new ones were formed very frequently, and airlines left one alliance group to join another. Such turbulence seemed to bring a measure of cautiousness and perhaps of fear, if not paranoia, into the way airlines were willing to discuss alliances. Indeed, in the alliance frenzy of the late 1990s it was sometimes difficult to tell whether an airline was a competitor or a partner.

In 1990, the industry sources listed 172 alliances, 82 of which involved equity investment (Airline Business, 1990). In 2001, there were well over five hundred airline alliance agreements among some two hundred airlines (Airline Business, 2001). Today nearly all major international airlines and most small and mediumsized airlines are parties to some kind of partnership. As to the success of the alliances, it has been suggested by Lindquist (1999) that in terms of survival, the success of airline alliances has improved significantly from the early 1990s.Overall, about 70 per cent of the alliances formed in the late 1990s have survived, domestic alliances having clearly been more durable than regional or intercontinental ones.

Most alliances are between two partners, but in the late 1990s arrangements of multiple participants emerged. Today there are four major airline alliance groups. Star Alliance led by Lufthansa and United Airlines and OneWorld led by American Airlines and British Airways each have about 20 per cent of the world passenger market; the other large groups are SkyTeam led by Air France and the alliance built around KLM and Northwest Airlines. Moreover, most alliances are between airlines from different countries, though there also are alliances between carriers of the same nationality. In addition, most airlines have 
several alliances, including domestic and international alliances. Air France had the largest number of alliances in 1999 with 33 arrangements, all but one with foreign partners (Airline Business, 2000, p. 48). In the late 1980s and early 1990s it was fairly common to seal an alliance with equity cross-ownership, but today only around one-tenth of the airline alliance arrangements involve equity. It seems that crossownership arrangements, typically between 5 and 30 per cent of equity, proved disappointing in terms of tangible advantages through enhanced coordination or trust. Table I summarizes the evolution of alliances in the airline industry from the pre-1980s era until today.

From a strategic perspective, airline alliances are a specifically interesting phenomenon. As alliances engage most of the world's airlines, they have become an inherent part of the 'task environment' of airlines (cf. Astley and Fombrun, 1983) and shaped the outlook of the entire field (cf. Scott, 1995). Organizationally, they are complex, heterarchical and dynamic networks, and are thus in many ways unique constellations (see also Borys and Jemison, 1989; Doz, 1996; Ring and van de Ven, 1994; Spekman et al., 1998). They are highly asymmetric and consist of multilateral links of different strengths between more or less autonomous partners. Internally, airline alliances are, however, often more unstable than one could expect. Unlike in tighter forms of network, airlines involved in alliancing apparently have to constantly negotiate a 'tradeoff between autonomy and survival' (cf. Pfeffer and Salancik, 1978), which means that the co-operative relationships are constantly renegotiated and subject to bargaining. Although portrayed as long-term cooperation and developing networks, the partnerships also appear to be easily broken as airlines switch from one alliance to another. Despite the clear rationalities behind alliances, they also often seem to provide limited gains for the parties involved (see e.g. Oum et al., 2000). 
Table I. Evolution of airline alliances

\begin{tabular}{|c|c|c|c|}
\hline & Pre-1980s & $1980 s$ & 1990 s and 2000 s \\
\hline Prevalence & Very rare & Rare & Very common \\
\hline $\begin{array}{l}\text { Nature of } \\
\text { building airline } \\
\text { alliances }\end{array}$ & $\begin{array}{l}\text { Very limited scope } \\
\text { Technical in nature } \\
\text { Often reflecting } \\
\text { national interests }\end{array}$ & $\begin{array}{l}\text { Bilateral } \\
\text { Often equity-involved } \\
\text { Driven by marketing }\end{array}$ & $\begin{array}{l}\text { Bilateral and multi- } \\
\text { partner } \\
\text { Strong groupings } \\
\text { around largest airlines } \\
\text { Broadening scope: } \\
\text { sourcing, production, } \\
\text { marketing, branding }\end{array}$ \\
\hline $\begin{array}{l}\text { Stated role of } \\
\text { alliances } \\
\text { in airline } \\
\text { strategies }\end{array}$ & Insignificant & $\begin{array}{l}\text { Increasingly important } \\
\text { for some medium-sized } \\
\text { airlines }\end{array}$ & $\begin{array}{l}\text { Essential for practically } \\
\text { all kinds of airlines } \\
\text { A 'must' for various } \\
\text { reasons }\end{array}$ \\
\hline
\end{tabular}

Source: Compiled from Air Transport Intelligence News Archive \& Annual Statistics.

Airline alliances are consequently an especially interesting case where particular strategic ideas have emerged and grown to dominate strategizing in the field. This development is usually seen as produced by 'wider socio-economic forces' or as a 'natural' development. Yet such perspectives often seem to forget that these alliancing ideas have been constructed without a clear 'blueprint' (i.e., few examples and practices from other industries that would guide the present process), that the organizational forms called alliances actually vary greatly across the different constellations, that the 'strength' of specific alliances often turns out to be questionable, that the meaning of alliances seems to vary greatly for different actors, and that the current strategic 'musts' related to alliances are, to a significant extent, discursively constructed. In our view, this calls for analysis of the discursive processes and practices involved in airline alliances.

\section{METHODOLOGY}

Our methodological starting point is to draw on critical discourse analysis. Our analysis is based on the CDA framework of Fairclough (1997) in which one can distinguish three levels of analysis: textual analysis focusing on individual texts, discursive analysis that concentrates on the characteristics of socially and societally significant discourses, and socio-practical analysis that grounds the discourses in specific social and societal contexts and enables one to 
understand the role of discourses as social and societal forces. In the present analysis, we, however, focused on the discursive level.[1]

A guiding idea in our research efforts was to be able to map strategizing processes and uncover discursive practices in airlines without artificially creating boundaries in the sensemaking and sensegiving processes across the airlines. What we were looking for was close to the classical idea of 'naturally occuring talk' (see e.g. Potter and Wetherell, 1987) in that we wanted to examine how different actors make sense of the alliance strategies in different forums, settings and situations. Therefore, we gathered empirical material from several sources, including the media and interview situations triggering specific kinds of reflection. We, however, focused our attention on mid-sized international European airlines, all of which are involved in an alliance. Our sources can be classified as follows (for details, see Appendix B):[2]

1. Press. This includes articles from both the specialized aviation press as well as general newspapers. A total of five airline business-related publications and three aviation online news services were monitored, covering a timespan from January 1995 to December 2000. In addition, three online archives of general newspapers and 12 weekly or monthly business magazines were examined, going back in time between two and five years. This category only includes material written by third parties (i.e., journalists and industry observers). Press releases and press interviews given by executives were grouped under category 2 .

2. Public relations. This refers to material issued directly by the airlines, which is destined for the public and the financial community. It includes press releases, statements made in annual reports (we examined the annual reports of 14 airlines between 1993 and 1999/2000), and statements made by airline managers in press interviews.

3. An online discussion forum on airline alliances. This discussion forum has been in place since June 1999 at the website of an aviation industry online news service provider. We monitored statements made by participants who had identified themselves as 'airline employees'. Defining their exact position was not possible, but it is assumed that they mostly come from front-line to middle ranks. 
4. Top management (CEO or vice president) interviews. A total of 12 interviews with nine interview partners. Interviews lasted between 45 minutes and two hours. They were taped, and later transcribed verbatim; two informants asked not to have their answers tape-recorded, but notes were taken.

5. Middle management and supervisor interviews. Six interviews, lasting from 45 minutes to just over one hour. Five were taped and later transcribed verbatim. One interview was conducted via electronic mail.

6. Front-line staff (ground operations, check-in, passenger services) interviews. Nine interviews, all lasting around 30 minutes each. They were tape recorded and excerpts were transcribed verbatim.

The 24 interview partners (who all had a minimum of five years experience with their respective company) came from ten different airlines. The interviews were conducted in a semi-structured way. Interviewees were asked to talk about the alliance-related events that affected their company and their own work. Since one purpose of the interviews was to filter out key themes, the interviewer usually refrained from addressing specific topics and instead asked the interviewees to elaborate on subjects, which they themselves had brought up. In many cases, the interviews turned into somewhat amicable 'shop talk', with interviewees being fairly relaxed, talkative, and willing to express their own opinions and concerns. For our analysis, this served as an important contrast to the more official published statements.

In addition to this material, the authors could draw on findings from participant observation; two of the authors themselves have several years of working experience in the air transport industry in general and with a total of four airlines; they have been researching airlines for the past 15 years. In addition to the formal interviews described above, they could draw on informal contacts and numerous discussions with managers from different airlines.

Continuous refining and specification of our ideas characterized our analysis. In crude terms, our analysis proceeded in three stages. First, we looked for specific themes that characterized the discourse on airlines and airline alliances. Overall, the strategy talk on airlines appeared to focus on two themes: 'financial problems' and 'need to change'. With regard to the more specific discussions on alliances, we could identify and focus on the following themes: 'strategic benefits', 'independence' and 'cooperation problems'. 
Second, we examined the discourses that appeared to dominate the discussions around these themes. In this process, we in particular mapped out how local discourses are linked with broader societal discourses. We could clearly identify 'traditional' discourses where airlines were linked with their historical role in society and with 'nationalism' as a discourse and ideology (see e.g. Anderson, 1983; De Cillia et al., 1999). We, however, also observed how these 'traditional' discourses were increasingly challenged and subordinated by specific variants of the discourse of 'global capitalism' (Fairclough, 2000) and 'neo-liberal ideology' (Bourdieu, 1988; Chomsky, 1999). We could also see the significant role of 'sociocultural' discourses, often linked with 'nationalism', where issues such as 'independence' could be seen as airline- and person-specific identification processes (see e.g. Vaara, 2002; Vaara, 2003; Vaara and Tienari, 2002). We furthermore made the distinction between more 'official' and 'critical' discourses, the latter often reflecting cynicism towards grand strategies. Based on this distinction of different discourse types, we could examine how the specific themes dominating strategy talk were framed and constructed in different ways. This enabled us to see how 'rationality', 'truth' and 'legitimacy' were indeed discursively constructed in the strategy talk. While examining the discourses, we also studied whether the discourses were directed towards an external audience (passengers, shareholders, the general public) or whether they reflected statements that were made internally, for example, among peers.

Third, to be able to understand the ways in which these discourses are utilized and activated, we then focused on the discursive practices employed in strategy talk. Although we could clearly see significant differences across airlines, we focused on those types of practices that characterized the strategy talk in most airlines. In this process, we could eventually focus on five specific discursive practices: (1) problematization of traditional strategies; (2) rationalization, objectification and factualization of alliance benefits; (3) fixation of ambiguous independence concerns; (4) reframing of cooperation problems as 'implementation issues'; and (5) naturalization of alliance strategies. These are presented and elaborated on in the following section. 


\section{THE DISCURSIVE CONSTRUCTION OF AIRLINE ALLIANCES AS DOMINANT STRATEGIC IDEAS}

\section{Problematization of Traditional Strategies}

A key discursive feature in the discussions around airline alliances was the problematization of traditional strategies. In rhetorics, construction of a 'problem' is usually seen as a key move paving the way for subsequent ideas presented as 'solutions' (see e.g. Perelman, 1977; Toulmin et al., 1979, ch. 16). In most of our alliance cases, this was discursively produced by de-legitimating the traditional role of the airlines. This was achieved by contrasting them with the contemporary ideals of 'corporatization', 'globalization' and 'financialization'. In particular, the arguments focusing on the poor financial perfor-mance of the airlines served as a powerful means in the rhetoric of the change protagonists.

Traditionally, airlines have played a 'special role' in society, and most discussions around airline alliances seem to reflect their particular socio-institutional heritage. One part of this heritage is linked with the development and control of air transport and regulation of the airline industry. For most of its history, that is, nearly 80 years, the world airline industry has been highly regulated and government controlled. This has also meant that the discourses around airlines have often focused on broader societal and institutional issues such as public service or safety. Especially in Europe, where governments have been significant owners of airlines, carriers have been required to provide services that have not been commercially viable; an example is a jet aircraft service to peripheral towns, when the demand would only justify a propeller aircraft or no service at all. The official strategies of these airlines have also traditionally included objectives such as how to promote better infrastructure or service.[3]

Another part of this heritage can be directly linked with 'nationalism' as an ideology (Anderson, 1983; Billig, 1995). While the leading US airlines have in recent decades been run as competing operations in an oligopolistic market, the European airlines - the focus of our study - have been strongly associated with the 'national heritage' of the country and served as 'national flag carriers'. Among other things, this has been reflected in the restriction posed by most countries on ownership and the tradition to give special status to domestic carriers. This discourse has also traditionally played a significant role in the economic and financial considerations around airlines. For example, several government interventions to 
save airlines in financial crises, such as Air France, have (re)produced a mythical element of 'government backup' or 'rescue' in discussions around airlines.

The traditional symbiotic relationship between airlines and nation states has, however, faced increasing pressure and broken down to some extent in discourse around airlines. To a significant extent, 'corporatization' and 'globalization' ideals - that can be seen as reflections of the discourse of global capitalism (Fairclough, 2000) and the neo-liberal ideology (Bourdieu, 1988; Chomsky, 1999) - have started to dominate the way airlines are discursively constructed. The neo-liberal ideology has also been part of deregulation and reinforced by concrete acts thereof, paving the way for competition and restructuring of the industry, following the examples of many other industries. In brief, deregulation has changed the rules of competition drastically in most major markets. However, this deregulation has been gradual, and it would not be exaggerating to state that the dominant view nowadays is that deregulation should proceed even more rapidly to turn the airline industry into 'a healthy business'.

In the discussions concerning specific airlines, the 'corporatization' and 'globalization' trends have clearly challenged and replaced the traditional view on airlines (see e.g. Oum et al., 2000). Jan Carlzon of the Swedish SAS provides a good example of framings directly challenging the previous discourse in the annual report for 1992:

In the future companies which obstinately uphold national interests and allow them to stand in the way of essential restructuring will have chosen the route towards elimination. At best they can expect to be a regional air transport operator which feeds traffic to one of the industry's giants ... But long-term survival requires stable platforms. It can only be achieved with cross-ownership, viable mergers or other forms which allow fundamental structural, financial and commercial integration. (Annual report, 1992, p. 1)

Jan Carlzon was actually one of the most important early protagonists of alliancing ideas. Even before first attempts to launch alliances, he had become a 'revolutionary', challenging traditional discourse in the airline context. In the mid- 1980s, Carlzon wrote a widely read management book Moments of Truth, including views challenging the management in the airline industry context. In 1985, Carlzon predicted that there would be only five major airlines in Europe by 1995 and declared that SAS wanted to be one of them. What is 
important in this context is that SAS was indeed one of the first airlines to pursue an alliance strategy in Europe and in the Americas, but eventually had to discard all of its minority investments.

In the late 1990s, these de-legitimizing framings became increasingly dominant. Most of our cases were indeed characterized by a setting where the change protagonists mobilized corporatization and globalization themes while the antagonists were associated with the traditional 'old-fashioned' nationalistic way of thinking. The following is a typical example:

In the future, competition will not any more be between individual airlines but between larger groups. Because Finnair does not want to remain a corporation operating only in one area, to survive we need a right partner. (Finnair CEO Antti Potila, Kauppalehti, 23 June 1997)

As in numerous other cases where the top management of European airlines actively promoted and made use of the 'globalization' theme, the CEO of the Finnish Finnair questions the previous 'stand alone' strategy of airlines. He depicts cooperation as necessary in the 'globalized' competitive scenario.

Economic and financial problems in particular were often brought to the fore as examples of 'the problematic state of affairs' in the airline industry and justifications for a need to 'change' or 'move on'. The industry was severely hurt by the recession in the early 1990s, but with the recovery of major economies and the very strong growth in air transport demand, it improved performance towards the end of the decade. From the perspective of creating 'shareholder value' - the ultimate objective in the neo-liberal ideology - the performance of the late 1990s was, however, far from satisfactory. In the public discourse, this unsatisfactory state of affairs was also gaining more and more attention as the airlines were forced to report their financial performance figures more openly than before. The following comment from a BCG consultant demonstrates this kind of thinking:

For shareholders with a long term perspective, airlines have historically been a high risk, low return investment. Consider the facts. Airlines have significantly underperformed relative to their local stock markets over the long run. Airline rates of return have been highly volatile. On average, airlines have even not earned returns 
that are sufficient to cover their cost of capital. (Airline Business, February 1999, p. 58)

In sum, the problematization of traditional strategies can be seen as the foreground for the legitimization of alliancing strategies. In the airline context, the problems discussed around the airlines were most often linked with the 'old-fashioned' thinking, usually directly challenging the traditional discourse emphasizing the 'special role' of airlines and the 'nationalism' associated with them. 'Corporatization', 'globalization' and 'financialization' were the themes, the mobilization of which gave discursive legitimacy to such problematization and paved way for alliances as the 'solutions' to the 'problems.'

\section{Rationalization, Objectification and Factualization of Alliance Benefits}

Another essential part of the discursive construction of airline alliances was the discussion concerning the benefits created by these arrangements. Rationalization of these benefits was indeed a key rhetorical strategy of the protagonists of alliances - both in cases of paving the way for subsequent strategic moves and in cases of justifying decisions already made. What is important to note, however, is that the rationalities put forth and discussed varied greatly depending on the social arena in question.

When the airline representatives justified their choices to general public, they most often constructed alliances as market-driven, benefiting both the customer (in terms of improved service) and the airline (in terms of enlarged networks and cost savings), as well captured in the British Airways Fact Book 2001 (p. 86):

More people want to fly to more places more easily and for greater value. Regulation or economics makes it impossible for any one airline to serve all these markets. In the drive for greater efficiency (as a means of providing greater customer value) airlines have largely achieved internal cost savings where they can. Future efficiencies will come from working more closely together, which means greater cost savings for the customer.

Behind this comment one can find the conviction that in many markets regulation makes it impossible for large airlines to grow internally - cooperation is the only realistic option. On the other hand, further internal cost saving efforts would, for instance, risk opposition from 
labour and result in strikes. In this context, it is important to remember that in the $1980 \mathrm{~s}$ British Airways incurred substantial losses, its reputation for reliability was poor, and its costs exceeded those of other major carriers. It was subsequently turned around through pursuing an 'addedvalue business strategy' and through a sustained cost-cutting programme, known as the 'survival plan', which caused numerous labour disputes. Against this background, it is not surprising that the representatives of British Airways have throughout the 1990s and early 2000s been among the most eager supporters of alliancing strategies.

It was especially the smaller airlines concentrating on regional and continental routes that saw access to the global route networks of larger carriers as the main rationale for alliancing. For example, the CEO of Finnair frequently promoted this rationale in the media:

The explanation for alliances is very simple. Air traffic is so much regulated that even large airlines cannot manage only by adding flights. One must ally, because customers demand global service. (Talouselämä, 30/1998, p. 12)

Announcements of cooperation often referred to the 'strategic compatibility' and 'excellence' of the partner chosen. The statements given by British Airways and Finnair when they announced their alliance are a good example of this:

We are proud to be associated with such an excellent airline as British Airways. Finnair's business environment has changed fundamentally during the last few years. To stay competitive we feel it is important to offer our customers the services of a global network. (CEO of Finnair, press release, February 1998)

British Airways today announced its link up with Finnair, the latest step in its plans to develop a comprehensive European-wide alliance. The joint British Airways/Finnair agreement will increase the choice and quality of service offered to customers. (British Airways press release, February 1998)

From the perspective of medium-sized airlines, the rationale of allying was also often linked with surviving increasing competition with larger airlines. These reflections were often grounded in classical strategic ideas of 'economies of scale' and 'market power'. Strategizing around Swissair in the late 1990s, before its bankruptcy in 2001, is a good example. The 
Swiss flag carrier had pursued a strategy of building alliances with smaller airlines over which they would seek to hold management control, usually cemented by equity stakes:

How else could companies active in relatively small markets possibly compete against giants from substantially larger markets? Alliances are becoming increasingly significant as it becomes obvious that many medium-sized companies can only survive and flourish in association with other like-minded and similarly positioned concerns. (Annual report, 1999, p. 14)

Our Qualiflyer alliance is needed simply so that Swissair and its partner airlines are big enough to hold up against the really big boys. That costs money before it earns money. (Philippe Brugisser, then CEO of Swissair, in a press statement, November 2000)

The managers of the airlines also frequently pointed to issues such as 'risk sharing' in competitive markets. In an interview, the vice president of a relatively small airline located in central Europe discussed their competitive situation, which was characterized by heavy competition (two or three competitors on each route). His conclusion - as that of most other representatives of medium-sized airlines - was that alliancing was mainly to avoid overcompetition:

For an airline of this size, it is of infinite importance to have these cooperations, there are many routes that in these heavily competitive markets are just not viable economically. So we enter these cooperations to optimize things - we say okay, let us split the economic risk on this or that route.

While justifications related to reduction of competition were not legitimate arguments in the public arenas or media, they were often used in the internal discourse of the airlines. For example, the CEO of a smaller airline that had directly competed with a much larger airline out of the same hub airport admitted in an interview that they had joined an alliance to avoid open competition:

Having the agreement with [airline $\mathrm{X}$ ] could bring us alignment with [airline $\mathrm{X}$ ] instead of war with our main competitor. 
More critical reflections concerning the anti-competitive implications of alliances were rare. However, such criticism could be found, for example, in the online discussion forum:

I'd think the ultimate linkage is when one airline flies a certain city-pair and all the code-share partners share the revenues and expenses. That's the part that is dangerously anti-competitive. (Airline amployee)

It is important to note that during the late 1990s many of these rationalizations grew into 'objectified' parts of the strategy talk around airlines. This could also lead to factualization, that is, taking specific benefits for granted in particular contexts. It is important to emphasize in this context that most of these factualized benefits were, however, estimates and speculations about future benefits created over time, not achieved benefits. These rational benefits thus served as powerful constructed arguments for justifying specific alliances. In most discussions, the antagonists or critics found it very hard to question these benefits. Interestingly, this was often related to a peculiar power/knowledge imbalance as usually only the corporate protagonists had access to the information needed to evaluate the benefits.

It is interesting to note that most of the alliances seem to have been unsuccessful in reaping such benefits, as the more critical comments below illustrate (see the section 'Reframing of cooperation problems as "implementation issues" '). In a sense, our analysis suggests that the rational benefits appear to be overestimated and the problems in achieving them underestimated in discourse around alliances.

In sum, an essential part of the discussions around airline alliances was rationalization of the benefits created by allying. Although the discursive framings varied across different arenas, many of these rationalities were over time objectified and became an inherent part of the strategic vocabulary. This also frequently led to a problematic factualization of alliancing benefits; in many cases their existence was taken for granted without closer analysis.

\section{Fixation of Ambiguous Independence Concerns}

Related to the specific socio-cultural heritage of airlines, the question of 'independence' became a major topic in strategizing. This 'independence' theme was most prominent in the reactions of those who appeared to resist the proposed or planned alliances, reflecting specific concerns over the loss of autonomy often mentioned in the alliance context (Gulati, 1995; 
Kleymann and Seristö, 2001) or different forms of organizational resistance to institutional change (see e.g. Oliver, 1991). In strategy talk, this was an inherent part of the 'socio-cultural' discourse characterized by strong identification with the airline and the nation in question (for analogous findings, see Vaara, 2002; Vaara and Tienari, 2002). In these texts, the front-line workers often identified strongly with the airline, the independence of which was taken as a value per se. Drawing on a discourse of 'banal nationalism' (Billig, 1995), the airline was in many cases portrayed as a national symbol whose independence appeared threatened, as the following excerpt illustrates:

I think the Finnish people have always wanted to be independent . . If there were no more Finnair, I think this would be a big shock for the Finnish people. (Check-in officer)

This type of a 'partisan' approach often reflected strong emotional attachment, as the following shows:

The CEO of SAS said in the news that some day, maybe SAS and Finnair will be in the same alliance. And that sounds terrible. That sounds terrible to me . . It's in my heart. I feel that I belong to this company. (Ramp agent)

This particular comment is illuminating as it illustrates how such emotions are linked with deeply held ideas of 'nationalism' associated with the airlines in question. In this commentary, the person associates Finnair with Finland and SAS with Sweden, although SAS is actually a Scandinavian (not only Swedish) airline. The comment has to be put in the context that Sweden and Finland have often been constructed as fierce competitors in different social arenas. For example, Ericsson and Nokia in mobile phones have represented and reproduced such rivalry in the business press. Especially in Finland, 'Finnishness' has often been reconstructed in relation to 'Swedishness', which explains the direct association of SAS with Sweden (see also Vaara and Tienari, 2002). Similar problematic relationships also exist between airlines of other neighbouring countries in Europe. For example, the discussions around the partnerships of Swissair and Austrian Airlines with German Lufthansa often brought deeply rooted nationalistic fears and prejudices to the fore.

These types of reactions among the employees were often directly linked with underlying concerns about future employment or control of specific operations. However, top 
and middle managers also often raised concerns about losing independence. This kind of 'independence' talk played a powerful role in resisting specific alliances; in specific discussions the protagonists found it very difficult to overcome. In fact, it appeared that in most alliances, the protagonists were quickto assure that the alliance would not 'sacrifice independence', 'challenge autonomy', imply 'losing control' or 'destroy' specific knowledge or values of the airlines. An illustrative example is the reflection concerning the future of Swissair, which was one of the most respected European airlines and a national emblem before its demise in late 2001:

\section{Swissair Will Remain Swiss - CEO Says}

SAirGroup chief executive Philippe Bruggisser dismissed media reports that the group may sell airline unit Swissair and defended his controversial alliance strategy. 'I hope to be able to tell my grandchildren that Swissair is Swiss', he told Blick newspaper in an interview printed on Saturday, adding he did not even have grandchildren yet. (Airwise online News Service, 20 November 2000)

Alliances could be justified by contrasting them with other possible future scenarios, such as being acquired. For example, a vice president of a smaller airline described how they chose to join an alliance group to keep their former partner - an airline much larger in size - from obtaining a blocking minority in the smaller airline:

We let [Airline A] know that it was not in our interest that [Airline A] gets close to a blocking minority [in speaker's airline]. Why? Because we would like to stay an independent airline as long as possible. That won't be possible forever, probably, but we intend to [try]. We see no reasons at the moment to . . . let me say hastily precipitate ourselves into the financial hands of another airline. (Vice president)

Joining specific alliances could also be legitimated by pointing to other alliance structures as threatening, as the following excerpt concerning Swissair exemplifies:

The head of SAir group (Swissair), Phillippe Bruggisser, is a typical Swiss: he prefers doing it alone, and he prefers to gather a troupe of smaller second-league partners around his airline to joining one of the big global alliances. Because Swissair would only play second fiddle in a cooperation with giants like British Airways or Lufthansa, and Zürich would be no longer a hub in its own right, but rather a feeder airport for 
Frankfurt or London. Doing it alone corresponds to the Swiss national character, and this policy so far has been sanctioned by SAir's board and shareholders. (Frankfurter Allgemeine Zeitung, 22 November 2000)

When discussing different approaches in alliances that were already established or just being formed, the interviewees frequently reverted to a 'buffering' approach. This meant explicit protection of one's independence against the other airline partners. The following is a typical example of this type of reflection, where a senior executive welcomes disagreements between the two (very large) 'lead carriers' as it allows his own airline to be more influential:

[In alliance group Z] you have the strange position where the two potential leaders can often be at odds and it allows the smaller airlines to be more influential. So from a [Alliance group] point of view that's a weakness, from a small airline's point of view it is an advantage. (Top manager)

The CEO of one smaller European airline pointed to Lufthansa as an especially "overwhelming" partner in the Star alliance, and thereby justified their own and partner airline Finnair's decision to join the OneWorld alliance group instead:

The way I interpret Star, and we had a lot of discussions with Lufthansa before we chose, the way I interpret it is that this alliance is driven very heavily by Lufthansa, and ... like ... the characteristic of Lufthansa is ... that ... they push you very hard, and ... you have to conform [laughs]. So there isn't an awful lot of room for dissent if you are a small carrier. [laughs] I think, you know, the way for our friends in Finnair in OneWorld is a healthier place to be at this stage.

Interestingly, a "healthy place" was considered one where dissent and nonconformity - or relatively autonomous decision-making - was allowed for even a small partner.

One consequence of this was that in most cases, the alliancing strategy evidently meant (re)production of 'countervailing myths'. In discussions on most alliances, we frequently found inherent contradictions created by expectations of increasing 'synergy', 'rationalization' and other 'cooperation benefits' requiring increasing integration between the alliance partners and promises of retaining 'sovereignty' and 'independence'. This was also 
apparent in various interviews dealing with the practical problems in established alliances, as the following excerpt illustrates:

We just got cross-cultural business training a couple of months ago. It was most interesting and I would have been really happy to get it before that evaluation meeting started. I must say that in some meetings there were situations where I was really confused, what's going on, what is it that these people mean, you just feel the situation, they said something else, but you feel that something is missing, this does not match what they are saying. (Middle manager)

Typically, it is middle managers who are charged with implementing the interairline cooperation on a daily basis. They are therefore required to meet with their counterparts from other airlines on a regular basis and confront the ambiguities and contradictions created by the 'countervailing myths'.

While the decision-makers often appeared to rather skillfully balance between different discourses and make use of them when justifying the alliance decisions, different actors could also more or less intentionally take advantage of the ambiguous vision and strategy formulations when resisting particular changes, for example, in established routines or control of specific operations. For example, the managing director of a reputable airline discussed at some length the intention of his management team to remain independent. Alliancing was recognized as a commercial 'must', but he made it very clear that he would not want to let cooperation go as far as jeopardising his airline's independence. He described his airline's route system and product planning as follows:

Well, it has to be based on the [Alliance group] book. But apart from that we have all the freedom, and we are protecting that, let's say [laughs].

In conclusion, the deeply rooted concerns about 'independence' - usually closely linked with nationalistic discourse - were woven into the strategy discourse both by the antagonists and protagonists of alliances. These meant fixation of these independence concerns in the strategy discourse, showing in ambiguities and contradictions in specific alliance settings. 


\section{Reframing of Cooperation Problems as 'Implementation Issues'}

We could also detect more critical voices drawing from the problems experienced when cooperating with alliance partners and the disappointments in creating the benefits strived for. The discussions with the airline employees and the exchange of views in the airline discussion forum in particular tended to manifest and (re)produce a counter-force to the rhetorics of the corporate protagonists. These comments could clearly at times effectively question and undermine specific alliancing decisions, as the following framing illustrates:

Tripleseven [participant's alias], how does it feel to be in the company of such wonderful partners?!!

It'll be interesting to see how the French and Italians get on. Is it true that you've lined up Air Afrique and Air-India as the next members? (Airline Discussion Forum, June 2001)

The commentator, whose airline had just joined an alliance with airlines that did not have a reputation of providing a quality product, uses irony to criticize the alliancing strategy. The reference to Air Afrique and Air-India (not members of that alliance) is a rhetorical means to emphasize the poor reputation associated with the alliance.

In the interviews, statements pointed to problematic experiences in alliancing, but rarely questioned the idea of the alliance as such. Top-level managers often focused on inefficient decision-making processes with their partners. For example, alliance-level coordination mechanisms and meetings were perceived as tedious and inefficient, as described in the following comments:

A medium-sized airline like ours does not welcome a flood of meetings, you know that it gets too much, and we are too small to send everybody to meetings, we are an operating airline, we have to fly planes. So, as a smaller airline, you have this maximum level of tolerance for these meetings and co-ordinating stuff. (Vice president)

A middle manager who during the two years prior to the interview had been working in an alliance coordination group and who had attended many meetings of this group, expressed typical disillusionment with the efficiency of these coordination sessions as follows: 
In these meetings [i.e., alliance co-ordination meetings], there is a problem in that they don't decide very much. There's a lot of stuff on the table, but they cannot reach a decision. (Middle manager)

Interestingly, the protagonists of specific strategies usually succeeded in framing the experienced problems as 'implementation issues'. Focusing attention on putting these strategies into practice can be seen as a key discursive practice that legitimates particular strategies, such as airline alliances. When this concerns potential criticism around alliances, it naturally also serves to protect the initial ideas in a particularly effective way.

One accepted way to keep an alliance from being 'dysfunctional' seemed to be the establishment of clear 'control', 'authority' or 'decision-making power'. When asked about which future development he expects to take place in the alliance group, one senior manager of a medium-sized airline answered:

I think the natural thing will be that if we have the right people in the OneWorld management company that it will assert itself and will look for, or will take, more authority. (Top manager, OneWorld member airline)

However, as representatives of small or medium-sized airlines, the interviewees in most cases also resisted the dominance of any one partner over the others. The following comment of a vice president describes a typical way of looking at these issues:

It doesn't really have to be so extreme that there is one partner who absolutely dominates, but there must be a very clear setting of goals, and there must be very clear setting of rules of the game . . Because otherwise, what happens is that they do not use all potential possibilities and that then, in the end, everybody loses, that means not just the customer but also the partners. And partially, well, it can happen in the extreme that partners compete with each other and go about co-operating with partners from other alliances ... As soon as things are arranged along strict rules, these problems disappear. (Vice president responsible for commercial cooperation agreements)

Also at intermediate management levels interviewees called for stronger commitment, and stronger leadership, as a solution for these operational problems. It appeared from the 
interviews that middle managers, who were often charged with the implementation of certain strategies agreed upon at higher levels, found themselves without clear guidance as to how to realize the ideas:

You need commitment first. It doesn't work like 'hey, let's change some practices now!'. You can do it up to certain points, but to continue, without the commitment, it doesn't happen. I think the key question is how to believe in the alliance, and how to believe in its benefits for all of us. And I think that everyone should see from our figures that we really should think more about the alliance and the competition with other alliances. (Middle manager, Airline A)

Even in the case where two airlines decided on a full merger (they called it a 'joint venture'), managers involved in coordination efforts found it difficult to discern any clear decisionmaking authority:

The main problem was that before they decide how to share . . They didn't talk about the leader in the joint venture; who should lead. I hope that in the future they first start o talk about this, and then of the integration, because it was a big job to be one organization. (Middle manager, Airline B)

The OneWorld alliance in particular appeared to be a 'too democratic' environment. The following comment was made by a middle manager before OneWorld established its own 'alliance management company' in an effort to streamline the decision-making processes between members:

It's really too democratic, this OneWorld. It doesn't benefit the alliance. (Middle manager, OneWorld member airline)

A middle manager, who had worked in several alliance co-ordination committees, expressed her disappointment with what she initially saw as a good concept:

There was a good start, I have to say. And that's what bothers me most; the start was so good, the brand is good, the image is good, everything is good, but it's a nice balloon without anything in it, it's just hot air. I like the branding, it's really nicely done. But then, it doesn't go further. There was some nice training and [laughs] nice 
road shows, everything in the beginning, and people were really involved. Now it's implemented or not, it's - headless.

Front-line employees, in turn, sometimes went to great lengths to tell stories about how things went wrong when cooperating with a partner. As a supervisor put it:

At work, I'm afraid I have to say that it [i.e., the alliance] hasn't worked out as well as the plans. For the customer. There's still a gap between how much responsibility we have and how much power we have - or don't have. (Supervisor)

Others, drawing on 'cultural' discourses, explained cooperation problems by cultural differences. For example, a middle manager at Alitalia explained the failure of the planned merger between Alitalia and Dutch KLM as follows:

Culturally we are really different. From my point of view this was one of the problems with the alliance ... But on the other hand Italian people reach the same aim in a different path. (Middle manager)

It should be emphasized that this material points to an institutionalization of specific organizational mechanisms in the alliance context and particular alliance management techniques. For example, 'alliance governance', 'alliance leadership' and 'cross-cultural alliance management' emerged as significant themes in the discourse on cooperation problems. While undoubtedly needed to cope with the organizational and managerial challenges created by alliances, this can also be taken as discursive evidence of the managerialization and technologization of specific issues, such as cultural concerns.

In sum, important in the discursive construction of airline alliances was the disassociation of the initial strategies (alliances) from their implementation. This resulted in discursive dynamics where much of the criticism arising from practical problems was directed at the execution and management of alliances, and thus did not lead to a questioning of the alliance strategies per se.[4]

\section{Naturalization of Alliance Strategies}

Our material strongly indicates that the airline alliances were increasingly explicitly portrayed as 'inevitable' strategic choices. This 'no choice' setting can be seen as a product 
of the kinds of discursive moves discussed above. However, the discussions around airline alliances also seemed to be self-constructive and selflegitimating as examples of alliances (re)produced the apparent new structure of the industry. The alliances of specific airlines put explicit pressure on others to ally, creating a 'domino effect'. As a top manager put it:

If there was no other alliance grouping formed, I don't think you'd need to join [alliance name]. Once other alliances form, they suck existing traffic into their network so you have to create a parallel network to make sure that you keep your traffic.

This kind of discourse seemed to dominate the reflections of most executives. In our interviews, expressions of the inevitability of alliancing were indeed very frequent.

It's inevitable that we'll end up linking with someone at some stage, in some form. (Top manager of a non-allied airline)

We found that if you didn't align yourself to one of the global groups, you were in danger of finding your interlining ability curtailed ... So the danger was that our ability to operate a global network would be contracted year after year. Priority would be given by the alliances to their own members and therefore we wouldn't be able to offer a global network. So that's the danger, I think, of standing alone. It's fine for point-to-point traffic, but if you have a high percentage of connecting traffic you could find your ability to offer them traffic or to get feed in to your system very much curtailed. (CEO of a small, allied airline which depends on connections via a hub airport dominated by its larger partner airline)

I believe that it's quite difficult to survive in the competitive environment without alliances. You have to choose an alliance that makes sense in the area [where] you are acting. (Top manager)

Not surprisingly, such inevitability was increasingly used as a specific rhetorical framing by the protagonists, as the following example illustrates:

Delta will proceed aggressively with worldwide alliance discussions in the future, not just because alliances are desirable from a business standpoint - although they are but also because we must. Airline alliances are revolutionizing the nature of 
worldwide competition, and Delta intends to be a leader as these changes occur. (Annual report, 1998, p. 5)

In the extensive material we examined, little attention was usually focused on elaborating other strategy alternatives, which is a clear indication of the naturaization of airline alliances as strategic ideas (Fairclough, 1997). In many discussions created around specific alliances, airlines and their decision-makers were consequently placed in a position where their strategic options appeared very limited. To put it crudely, in this kind of scenario, the question was no longer whether to join an alliance but which alliance to join. Interestingly, even though alliancing was taken to be an unavoidable fact of life, the current scenario and partnering constellation were assumed by some actors to be still quite unstable, as reflected upon by a key decision-maker:

My own sense is that it [the current alliancing scenario] will collapse, and but it might take up to five years, six to five years, but I think it will collapse. And I think when it does, everybody will re-examine their position. I think you will certainly get some consolidation; you will get consolidation in Europe ... I think something will happen, and then I think the alliances will really be up for grabs, because you will get some marriages, some consolidations, and then you're going to get a different series of alliances, but real alliances - but that's looking at the crystal ball. (Top manager)

This inevitability or permanence of airline alliances may, indeed, be relative. In fact, very few in the industry would be surprised if one of the major alliance groups suddenly dissolved, which would then most likely start a round of regrouping in the industry. Such restructuring could also involve mergers and acquisitions, depending on the stance taken by competition authorities. Such developments could also discursively lead to new innovations where the 'alliance' concept could be replaced by a 'network', 'group', 'partnership', 'union', 'consortium', or some other more catchy word. For medium-sized European airlines, the focus of our study, the times are very testing. It appears to be commonly accepted that being a member in the alliance game is a must; however, aligning operations with other partners is expensive, there are barriers to realizing the proposed benefits, and the risks of joining the wrong party are sizeable.

In conclusion, by the late 1990s, the discussions around airlines were increasingly characterized by the naturalization of alliance strategies. This naturalization was shown in 
that 'inevitability' grew into an increasingly important theme, that new decisions to ally required less specific justification than before, and that the strategy discussions offered very little space for alternative strategic options.

\section{DISCUSSION: THE ROLE OF DISCURSIVE PROCESSES AND PRACTICES IN STRATEGIZING}

The starting point of our analysis has been that in most contemporary organizations strategizing involves a myriad of discursive processes, the exact spatial and temporal mapping of which is impossible. This approach is theoretically and methodologically challenging because it implies that we can only examine 'glimpses' of these processes. However, this approach enables us to examine and understand some of the key features and inherent complexities that are impossible to reveal with traditional approaches to strategy. In our analysis of airline alliances, we have in particular illustrated how strategizing transcends various kinds of organizational and hierarchical boundaries as people make sense of what is happening in their own and others' organizations, how strategizing is bound by various types of discourse that the people involved are not always aware of, how strategizing involves a dynamic of destabilization and stabilization of particular meanings, and how the meanings attached to specific strategic ideas can vary greatly depending on the arena and social context.

The specific contribution of our analysis is that it distinguishes and makes visible such micro-level discursive practices that are usually missed by strategy scholars - not to speak of practitioners. Although the discursive processes involved in strategizing are contextspecific and the consequent strategy constructions may only be temporary fixations, we argue that the discursive practices identified in our analysis are likely to characterize most strategy creation processes. Discursive practices which problematize traditional strategies, rationalize, objectify and factualize the benefits related to specific strategies, fix concerns about losing control/power, disassociate strategic ideas from their implementation, and tend to develop a 'no choice' scenario can be seen as inherent parts of the strategies of the contemporary era of global industrial restructuring. Steps such as constructing a problem scenario and explication and rationalization of specific benefits characterize most rhetorical activity (see e.g. Perelman, 1977; Toulmin et al., 1979) but are especially relevant for reasoning in the management (or strategy) context. In the contemporary era of global industrial restructuring, concerns related to autonomy removal, losing control or independence, or sacrificing cultural heritage often 
have to be tackled or woven into strategy discourse. There is, for example, clear evidence that the discursive justification and legitimation of mergers and acquisitions involves analogous constructions where 'rationalistic' and 'cultural' discourses represent two powerful social forces (see Vaara and Tienari, 2002). The explicit disassociation of strategies as ideas from their implementation when dealing with the problems and disappointments of specific strategies also appears to be a frequent experience in strategizing. And finally, creating a 'no choice' setting seems to be an essential part of the naturalization of specific strategies.

By revealing and illustrating specific discursive acts, we are building an understanding of important micro activities and practices that make up strategizing. These intertwined processes involve cognitive, emotional and political elements as the actors (re)interpret and (re)create meanings, vocabularies and discourses. The cognitive element in these processes is the (re)creation of rationality that turns out to be discourse dependent. For example, relying on government back-up in unprofitable operations is perfectly rational within the traditional (discursive) frame of reference where airlines are seen as part of the infrastructure and national identity. However, within the frame of global capitalism, such interventions are simply not possible and profitability is thus more important than before. The emotional element in these processes is reflected in metaphorical expressions where actors portray and even glorify airlines as specific cultures and identify with them. In our material, the richest were the reflections around the 'independence' of the airlines. There were also strong emotional reflections in the expressions challenging the official corporate rhetoric in the airline discussion forum.

The political element in these discursive processes is especially relevant and prominent. The official corporate strategy rhetoric is usually targeted and persuasive and those resisting changes can also make purposeful use of specific rhetorics such as the discourse on 'independence'. This rhetorical activity can also be hypocritical in the sense that actors consciously try to persuade or convince others with such discourse and arguments in which they do not believe. In the examples above, one could easily interpret specific rhetorics of the corporate representatives focusing on alliancing benefits or assuring that 'independence' will not be lost as such. However, one should note that such hypocrisy may also be produced when statements and framings are read from and placed in different discursive frames (see also Brunsson, 1989). 'Independence' from a 'nationalistic' perspective may indeed mean something very different from participating as one among 
many in joint development of the alliance group (what the corporate representatives might have in mind). Finally, the discursive acts, as exemplified by the framing of problems experienced as implementation issues, may also serve purposes such as attribution of responsibility and failure to other actors or factors when the chosen strategies do not produce the desired benefits.

It is important to emphasize the self-constitutive features of strategy talk, which easily pass unnoticed in more action-oriented sensemaking analyses (see e.g.Weick, 1995) and in discursive analyses focusing on the active mobilization of discourses (see e.g. Hardy et al., 2000). In brief, as clearly illustrated in our material, the alliance discourse evolved into a selflegitimating and self-naturalizing social force. On the one hand, in the clearest cases, the "no choice' setting appeared to leave decision-makers with no other legitimate option. On the other hand, joining an alliance or creating more cooperation plans appeared to be naturalized and thus required no specific justification by the end of 1990s. Recognizing the role of such discursive forces is, in our view, crucial in contemporary settings where media coverage forces one to continuously campaign to (re)create a positive image vis-à-vis customers, existing personnel and potential recruits, institutional investors, and, in cases like this, the other players as potential partners as well.

In addition to making us better comprehend and conceptualize the complexities of strategizing processes, this analysis contributes to our understanding of two issues that have been difficult to deal with in traditional strategy research: how strategies designed to create a competitive advantage grow into 'fashions' that spread across the industries and how supposedly clear-cut strategies often entail internal ambiguities and contradictions. As to the creation of 'strategy fashions', there are obviously many 'concrete' or 'rational' reasons that explain social movements such as mid-sized European airlines outlining and implementing very similar strategies. However, it seems apparent that precisely the self-legitimizing and self-naturalizing dynamics of strategy discourse add to the pace and force of such 'fads' (see also Abrahamson, 1996; Benders and van Veen, 2001; Huczynski, 1993; Kieser, 1997). This discursive view thus also sheds new light on the 'uniqueness paradox' - that strategies devised to create competitive advantage (over others) often turn out to be very similar across the competitors - characterizing so much strategizing activity (see also Martin et al., 1983). 
The discursive view also helps us to understand the inherent ambiguities and contradictions in strategies. From a discursive perspective, these (often underlying) ambiguities and contradictions are produced through the dialectics of different kinds of framings. Rhetorically, ambiguity is often needed to justify strategies and gain acceptance in various social arenas. In our cases, the counterveiling myths of 'rational benefits' and 'independence' were sustained and (re)produced in the discourses and rhetorics around airline alliances. This ambiguity should not be dismissed as a curious discursive or rhetorical feature characterizing alliances that are just being established. In fact, it can be taken as an essential institutionalized characteristic of airline alliances.

Such ambiguity can be seen as 'a normal state of affairs' in organizations with both positive and negative implications (Denis et al., 1996; Meyerson, 1991). However, this ambiguity becomes problematic if and when it means that the organizational actors have very different views concerning, for example, the roles of the different parties and the control and coordination mechanisms of the alliance. Our evidence suggests that in some alliances these in-built contradictions can create positive dialectics where the different ways of interpretation serve to produce healthy tensions when particular alliances are being formed and institutionalized (see also Calori and Melin, 2001). However, in other cases, these internal tensions are obviously very central reasons for the cooperation problems, disappointments and break-ups frequently experienced in airline alliances (see e.g. Lindquist, 1999; Oum et al., 2000).

\section{CONCLUSION}

This paper has been an attempt to answer the call for new theoretical and methodological approaches that help us understand the complex micro-level processes involved in strategizing. We have aimed to contribute to our understanding of the discursive side of strategizing that has not received much attention in previous research in this area (see, however, Barry and Elmes, 1997; Hardy et al., 2000; Hendry, 2000; Lennie, 2001; Lilley, 2001). In particular, we have focused on the elaboration and empirical illustration of the micro-level discursive practices that characterize strategizing processes but have not been given explicit attention - to our knowledge - in any prior study in this area.

Our conviction is that the contribution of any theoretical approach becomes apparent only when used to examine empirical phenomena. In this paper, we have therefore explored 
the discursive construction of airline alliances as dominant strategic ideas. While we have done this to develop more in-depth understanding of the discursive dynamics of strategizing, we want to emphasize that airline alliances constitute a real-life strategic phenomenon that deserves attention in its own right. In fact, trying to understand how airline alliances have during the past decade become the legitimate strategy of almost all significant airlines is precisely the kind of question that strategy scholars need to examine. Although there are many other explanations for this restructuring of the industry, we think that our analysis clearly points to the central role of discourse in the justification, legitimization and naturalization of these strategies.

While arguing for a discursive perspective, we want to emphasize that this approach is in no way theoretically or methodologically unproblematic. First, the ontology and epistemology of discourses and the appropriate means of discourse analysis are questions for debate in the social sciences (see e.g. van Dijk, 1997). We have here argued for an approach that emphasizes the linkage between discourse and social/organizational practice. Such a 'realistic' approach is for us a logical choice for strategy researchers exploring the relationship between idea generation and 'organizational reality' (see also Reed, 1998). This approach allows one to contrast the discursive side of strategizing with other meaningful views such as the conceptualization of strategizing as political activity.

Second, there is the problem that discourse analysis methods, more than anything else, portray the appropriate ways of representing ideas in various social forums. Again we believe that linking discourses with socio-cultural practices is a choice that helps to evaluate whether the strategizing reflected in written documents has a major impact on organizational processes or whether in specific contexts it is more 'empty rhetoric' than anything else. We also want to point out that any discourse analysis should be very sensitive to the various types of socially defined speakers and audiences. Singling out different types of audience can be seen as a major challenge for future research.

While we have tried to study strategizing in a context where we can point to the similarities in the strategizing processes of different airlines and examine the apparent flow of ideas across the corporations, future studies could focus on more limited empirical material. These studies could go further in examining more closely the discursive and rhetorical strategies and moves through which different social actors construct strategic ideas. Such 
studies could also focus on specific cases where the role of the rhetoric of key managerial actors could be highlighted. Future studies could also concentrate on specifically widespread texts and deconstruct those to highlight specific discursive and rhetorical elements in the legitimization and naturalization of specific strategic ideas.

With regard to the airline context, the new crisis brought about after September 11th may be seen as a turning point in airline alliancing. One the one hand, it seems that the crisis can add more fuel to the arguments of the change protagonists as the financial and other problems of the airlines are more acute than ever. This could lead to further strengthening of the alliance strategies and also play down the independence discourse. On the other hand, it may turn out that these developments trigger the development of new airline strategies such as mergers and acquisitions. In any case, we think that this deserves special attention by scholars trying to understand what is happening in airlines and how new strategy discourse could be emerging.

In conclusion, we believe that the discursive approach helps to shed light on the linguistic aspects of strategizing that have not received adequate attention in previous work in this area. Like any approach, it does not provide the whole picture and at best serves as a complement to other views on strategizing. A special difficulty lies in the fact that the microlevel discursive processes and constructions are difficult to capture, but the problem is that ignoring them easily sustains an overly simplistic view on strategizing.

\section{NOTES}

[1] In our view, the 'realist' ontological starting point, which accepts that specific discourses construct social reality but that this occurs within, around, and because of, pre-existing structures, is a fruitful starting point to be able to examine the role of discursive processes in strategizing. In Reed's (1998, p. 212) words: 'If this realist ontology is accepted, then it becomes possible to treat discourses as generative mechanisms or properties possessing certain "performative potentials",

[2] Most of the material collected was in the English language. Some of the interviews and some articles had to be translated from other languages (German, Finnish, Spanish and Portuguese). 
[3] It should be noted that this type of discourse has not vanished from the airline context. For example, even a superficial reading of the public discussion around the huge subsidies given to US airlines suffering from the September 11th ramifications reveals the linkage to the broader public mission of the airlines.

[4] A political interpretation of some of the discussions created around specific alliances is that by focusing attention on implementation issues, those justifying the decisions made (alliances) could attribute disappointments and failures to others.

\section{APPENDIX A: BROAD OVERVIEW OF CURRENT ALLIANCE GROUPINGS}

(Lead airlines marked with *)

\section{Star Alliance}

*Lufthansa

*United Airlines

Air Canada/Canadian

All Nippon Airways

Ansett Australia

Thai Airways

Singapore Airlines

Air New Zealand

VARIG Brasil

SAS

Austrian Group (Austrian Airlines, Tyrolean Airways, Lauda Air)

British Midland

\section{OneWorld}

*British Airways

*American Airlines

Iberia

LanChile

Aer Lingus

Qantas 
Cathay Pacific

Finnair

Wings

*KLM

*Northwest

Continental Airlines

Malaysian Air System

Sky Team

*Air France

*Delta Air Lines

Alitalia

Korean Airlines

CSA 


\section{APPENDIX B}

\section{Key Sources of Information (I): Airlines}

\begin{tabular}{|c|c|c|c|c|}
\hline Airline & $\begin{array}{c}\text { Annual } \\
\text { reports } \\
\text { (1993-99) }\end{array}$ & $\begin{array}{c}\text { Press releases } \\
(1998-2000)\end{array}$ & $\begin{array}{c}\text { Interviews } \\
\text { (during 2000) }\end{array}$ & $\begin{array}{l}\text { Other (participant } \\
\text { observation, } \\
\text { informal contacts) }\end{array}$ \\
\hline Aer Lingus & & $\checkmark$ & $\checkmark$ & \\
\hline Aerolíneas Argentinas & & $\checkmark$ & & $\checkmark$ \\
\hline Air Canada & $\checkmark$ & $\checkmark$ & & \\
\hline Air France & $\checkmark$ & $\checkmark$ & & \\
\hline Air Malta & & $\checkmark$ & $\checkmark$ & \\
\hline Alitalia & & $\checkmark$ & $\checkmark$ & \\
\hline American Airlines & $\checkmark$ & $\checkmark$ & & \\
\hline Austrian Airlines & $\checkmark$ & $\checkmark$ & $\checkmark$ & \\
\hline British Airways & $\checkmark$ & $\checkmark$ & & \\
\hline British Midland Int'l & & $\checkmark$ & $\checkmark$ & \\
\hline Canadian Airlines & $\checkmark$ & $\checkmark$ & & \\
\hline Delta Air Lines & $\checkmark$ & $\checkmark$ & & \\
\hline Deutsche BA & & $\checkmark$ & $\checkmark$ & \\
\hline Eurowings & & $\checkmark$ & & $\checkmark$ \\
\hline Finnair & $\checkmark$ & $\checkmark$ & $\checkmark$ & $\checkmark$ \\
\hline Iberia & & $\checkmark$ & & \\
\hline Japan Air Lines & & $\checkmark$ & & $\checkmark$ \\
\hline KLM & $\checkmark$ & $\checkmark$ & & \\
\hline LAN Chile & & $\checkmark$ & $\checkmark$ & $\checkmark$ \\
\hline Lauda Air & & $\checkmark$ & & \\
\hline Lufthansa & $\checkmark$ & $\checkmark$ & & $\checkmark$ \\
\hline Portugália & & $\checkmark$ & $\checkmark$ & \\
\hline Qantas Airways & $\checkmark$ & $\checkmark$ & & \\
\hline SAS & $\checkmark$ & $\checkmark$ & & \\
\hline Swissair & $\checkmark$ & $\checkmark$ & & \\
\hline Thai Airways Int'l & & $\checkmark$ & & \\
\hline United Airlines & $\checkmark$ & $\checkmark$ & & \\
\hline Virgin Atlantic & & $\checkmark$ & $\checkmark$ & \\
\hline
\end{tabular}




\section{Key Sources of Information (II): Press}

Covers timespan from 1995 to 2000.

(a) Airline-industry related press

Air Transport Intelligence Online News Service (http://www.rati.com)

Air Transport World

Airfinance Journal

Airline Business

Airwise Online News Service (http://news.airwise.com) and Discussion Forum

Aviation Week \& Space Technology

Flight International

(b) Business press

Asian Business

Brandweek

Business Week

The Economist

Financial Times

Forbes

Kauppalehti (Finnish Business daily)

Marketing

Marketing Week

Pointcast and Entrypoint online news services (http://www.entrypoint.com)

Talouselämä (Finnish Business Weekly)

Transportation and Distribution

(c) Newspapers and general magazines

Frankfurter Allgemeine Zeitung (German daily newspaper)

Helsingin Sanomat (Finnish daily newspaper)

Neue Zürcher Zeitung (Swiss daily newspaper) 


\section{REFERENCES}

Abrahamson, E. (1996). 'Management fashion'. Academy of Management Review, 21, 25485.

Airline Business (1990). Strategic illusions. July, 24-30.

Airline Business (2000). Annual survey on airline alliances. July, 46-93.

Airline Business (2001). Annual survey on airline alliances. July, 40-70.

Alvesson, M. and Kärreman, D. (2000). 'Varieties of discourse: on the study of organizations through discourse analysis'. Human Relations, 53, 1125-51.

Alvesson, M. and Willmott, H. (1996). Making Sense of Management: A Critical Introduction. London: Sage.

Anderson, B. (1983). Imagined Communities: Reflections on the Origin and Spread of Nationalism. London: Verso Editions and NLB.

Astley, W. and Fombrun, C. (1983). 'Collective strategy: social ecology of organizational environments'. Academy of Management Review, 8, 576-687.

Barry, D. and Elmes, M. (1997). 'Strategy retold: toward a narrative view of strategic discourse'. Academy of Management Review, 2, 429-52.

Benders, J. and van Veen, K. (2001). 'What's in a fashion? Interpretative viability and management fashions'. Organization, 8, 33-53.

Billig, M. (1995). Banal Nationalism. London: Sage.

Borys, B. and Jemison, D. (1989). 'Hybrid arrangements as strategic alliances'. Academy of Management Review, 14, 234-50.

Bourdieu, P. (1988). Acts of Resistance - Against the New Myths of Our Time. London: Polity Press.

Brunsson, N. (1989). The Organization of Hypocrisy. London: Wiley. 
Calori, R. and Melin, L. (2001). 'Micro Strategising: Dialectical Logic, Communicative Action and

Dialogue'. Paper presented at the European Institute for Advanced Studies in Management Workshop: 'Micro strategy and strategising', Brussels, Belgium.

Chomsky, N. (1999). Profit Over People: Neoliberalism and Global Order. New York: Seven Stories Press.

Cohen, M. D., March, J. G. and Olsen, J. P. (1972). 'A garbage can model of organizational choice'.Administrative Science Quarterly, 17, 1-25.

Czarniawska, B. (1997). Narrating the Organization. Chicago, IL: University of Chicago Press.

De Bono, E. (1984). Tactics: The Art and Science of Success. Cambridge, MA: MIT Press.

De Cillia, R., Reisigl, M. and Wodak, R. (1999). 'The discursive construction of national identities'. Discourse and Society, 10, 149-73.

Denis, J.-L., Langley, A. and Cazale, L. (1996). 'Leadership and strategic change under ambiguity’. Organization Studies, 17, 673-99.

Doz, Y. (1996). 'The evolution of cooperation in strategic alliances: initial conditions or learning processes?'. Strategic Management Journal, 17, Special Issue, 55-84.

Dunford, R. and Jones, D. (2000). 'Narrative in strategic change'. Human Relations, 53, 1207-26.

Fairclough, N. (1997). Critical Discourse Analysis: The Critical Study of Language. London: Longman.

Fairclough, N. (2000). 'Guest editorial: Language and neo-liberalism'. Discourse and Society, 11, 147-8.

Foucault, M. (1980). Power/knowledge, Gordon, C. (Ed.). Brighton: Harvester Press. 
Gulati, R. (1995). 'Does familiarity breed trust? The implications of repeated ties for contractual choice in alliances'. Academy of Management Journal, 38, 85-112.

Hardy, C., Palmer, I. and Phillips, N. (2000). 'Discourse as a strategic resource'. Human Relations, 53, 1227-48.

Hendry, J. (2000). 'Strategic decision making, discourse, and strategy as social practice'. Journal of Management Studies, 37, 955-77.

Huczynski, A. A. (1993). Management Gurus: What Makes Them and How to Become One. London: Routledge.

Johnson, G. and Bowman, C. (1999). 'Strategy and Everyday Reality: The Case for the Study of 'Micro-strategy'. Paper presented at the 1999 EGOS conference, Warwick, UK.

Johnson, G. and Huff, A. (1998). 'Everyday innovation/everyday strategy'. In Hamel, G., Prahalad, C. K., Thomas, H. and O'Neal, D. (Eds), Strategic Flexibility: Managing in a Turbulent Environment. Chichester: Wiley.

Johnson, G., Melin, L. and Whittington, R. (2003). 'Guest editor's introduction micro strategy and strategizing: Towards an activity-based view'. Journal of Management Studies, 40, 1, 3-22.

Keenoy, T., Oswick, C. and Grant, D. (1997). 'Organizational discourses: text and context'. Organization, 4, 147-57.

Kieser, A. (1997). 'Rhetoric and myth in management fashion'. Organization, 4, 49-74.

Kleymann, B. and Seristö, H. (2001). 'Levels of airline alliance membership: balancing risks and benefits', Journal of Air Transport Management, 7, 303-10.

Knights, D. and Morgan, G. (1991). 'Strategic discourse and subjectivity: towards a critical analysis of corporate strategy in organizations'. Organization Studies, 12, 251-73.

Knights, D. and Morgan, G. (1995). 'Corporate strategy, organizations and subjectivity: a critique'. Journal of Management Studies, 32, 191-214. 
Lennie, I. (2001). 'Language that organizes: plans and lists'. In Westwood, R. and Linstead, S. (Eds), The Language of Organization. London: Sage.

Lilley, S. (2001). 'The language of strategy'. In Westwood, R. and Linstead, S. (Eds), The Language of Organization. London: Sage.

Lindquist, J. (1999). 'Overview of Alliance Development in the Airline Industry'. Paper presented at the 1999 Institute of Management Research Conference, Maximizing ROI of Airline Alliance, Paris, France.

Lyotard, J.-F. (1979). The Postmodern Condition: A Report on Knowledge. Manchester: Manchester University Press.

Martin, J., Feldman, M., Hatch, M. and Sitkin, S. (1983). 'The uniqueness paradox in organizational stories'. Administrative Science Quarterly, 28, 438-53.

Meyerson, D. (1991). 'Acknowledging and uncovering ambiguities in cultures.' In Frost, P. J., Moore, L. F., Louis, M. R., Lundberg, C. C. and Martin, J. (Eds), Reframing Organizational Culture. Newbury Park, CA: Sage.

Mintzberg, H. (1983). Power In and Around Organizations. Englewood Cliffs, NJ: Prentice Hall.

Norrman, R. (1993). Skapande företagsledning. Stockholm: Bonnier Alba.

Oliver, C. (1991). 'Strategic responses to institutional processes'. Academy of Management Review, 16, 145-79.

Oum, T. H., Park, J.-H. and Zhang, A. (2000). Globalization and Strategic Alliances: The Case of the Airline Industry. Amsterdam: Pergamon, Elsevier Science.

Perelman, C. (1977/1982). The Realm of Rhetoric. Notre Dame and London: University of Notre Dame Press.

Perelman, C. and Olbrechts-Tyteca, L. (1971). The New Rhetoric: A Treatise on Argumentation. Notre Dame: University of Notre Dame Press. (La Nouvelle Rhétorique: Traité de l'Argumentation. Presses Universitaires de France 1958). 
Pettigrew, A. M. (1973). The Politics of Organizational Decision-making. London: Tavistock.

Pettigrew, A. M. (1992). 'On studying managerial elites'. Strategic Management Journal, 13, $163-83$.

Pfeffer, J. and Salancik, G. (1978). The External Control of Organizations. New York: Harper \& Row.

Potter, J. and Wetherell, M. (1987). Discourse and Social Psychology. London: Sage.

Reed, M. (1998). 'Organizational analysis as discourse analysis: a critique'. In Grant, D., Keenoy, T. and Oswick, C. (Eds), Discourse + Organization. London: Sage.

Reed, M. (2000). 'The limits of discourse analysis in organizational analysis'. Organization, 7, 524-30.

Ring, P. and van de Ven, A. (1994). 'Developmental processes of co-operative interorganizational relationships'. Academy of Management Review, 19, 90-118.

Scott, R. W. (1995). Institutions and Organizations. Thousand Oaks, CA: Sage.

Segil, L. (1998). 'Strategic alliances for the 21st century'. Strategy and Leadership, 26, $12-$ 16.

Spekman, R., Forbes, T., Isabella, L. and Mac Avoy, T. (1998). 'Alliance management: a view from the past and a look to the future'. Journal of Management Studies, 35, 747-72.

Toulmin, S., Rieke, R. and Janik, A. (1979). An Introduction to Reasoning. London: Macmillan.

Vaara, E. (2002). 'On the discursive construction of success/failure in narratives of postmerger integration'. Organization Studies, 23, 213-50.

Vaara, E. (2003). 'Post-acquisition integration as sensemaking: Glimpses of ambiguity, confusion, hypocrisy and politicization'. Journal of Management Studies, 40, 4, 859-894.

Vaara, E. and Tienari, J. (2002). 'Justification, legitimization and naturalization of mergers and acquisitions: a critical discourse analysis of media texts'. Organization, 9, 275-304. 
Van Dijk, T. A. (1997). Discourse as Structure and Process. London: Sage.

Weick, K. E. (1995). Sensemaking and Organizations. Thousand Oaks, CA: Sage.

Westwood, R. and Linstead, S. (2001). 'Language/organization: Introduction'. In Westwood, R. and Linstead, S. (Eds), The Language of Organization. London: Sage.

Whittington, R. (1993). What is Strategy - and Does It Matter? London: Routledge. 